\title{
Perfil epidemiológico das infecções por COVID-19 no município de Parnaíba-PI
}

\author{
Epidemiological profille of infections by COVID-19 in the city of Parnaíba-PI \\ Perfil epidemiológico de las infecciones por COVID-19 en la ciudad de Parnaíba-PI
}

Recebido: 07/11/2021 | Revisado: 13/11/2021 | Aceito: 13/11/2021 | Publicado: 24/11/2021

Lucas Antonio de Oliveira Santos

ORCID: https://orcid.org/0000-0001-6024-0231 FAHESP/IESVAP, Brasil

E-mail: lucasantonio1452@gmail.com

Gabriela de Souza Mendonça

ORCID: https://orcid.org/0000-0002-7922-5995 FAHESP/IESVAP, Brasil

E-mail: gabyaraujo2007@hotmail.com

Viviane Alves da Silva

ORCID: https://orcid.org/0000-0002-4973-3219 FAHESP/IESVAP, Brasil

E-mail: vivianealvessilva1996@outlook.com Renata Paula Lima Beltrão

ORCID: https://orcid.org/0000-0002-3624-6171 Universidade Federal do Piauí, Brasil E-mail:rplbeltrao@gmail.com

José Lopes Pereira Júnior

ORCID: https://orcid.org/0000-0001-9519-9363

Universidade Federal do Piauí, Brasil

E-mail: josejrfarmaceutico@gmail.com

\begin{abstract}
Resumo
Introdução: O comportamento da pandemia de COVID-19 resulta de diversos fatores, tais como características virais, populacionais e emprego de medidas de controle do número de casos. A variedade de tais fatores em cada território é responsável por criar perfis epidemiológicos únicos, o estudo destes perfis é essencial para entender o comportamento da epidemia e planejar medidas de enfrentamento contra a doença. Para tal fim, o estudo atual propõe investigar o perfil das infecções pelo novo coronavírus no município de Parnaíba-PI. Objetivo: Traçar o perfil epidemiológico das infecções por SARS-CoV-2 no município de Parnaíba-PI. Métodos: Trata-se de um estudo epidemiológico descritivo secundário, o qual se utilizou de dados coletados através da ficha de notificação de casos de COVID-19, entre os meses de março de 2020 e 2021, não foram incluídos na análise os casos cujo os dados nas fichas de notificação estivessem incompletos. Resultados: Foram incluídos na análise 11.864 casos diagnosticados no período. Conclusão: Os casos analisados foram constituídos principalmente de mulheres, e se apresentaram principalmente em faixas etárias de 20 a 59 anos, com pico de incidência na faixa de 30 a 39 anos. A grande maioria não relatou comorbidades ou situações de risco. Os sintomas mais referidos foram febre, tosse e dor de garganta.
\end{abstract}

Palavras-chave: SARS-CoV-2; COVID-19; Coronavírus; Perfil de saúde.

\begin{abstract}
Introduction: The behavior of the COVID-19 pandemic results from several factors, such as viral and population characteristics and the use of measures to control the number of cases. The variety of such factors in each territory is responsible for creating unique epidemiological profiles, the study of these profiles is essential to understand the behavior of the epidemic and plan measures to fight the disease. To this end, the current study proposes to investigate the profile of infections by the new coronavirus in the city of Parnaíba-PI. Objective: To trace the epidemiological profile of SARS-CoV-2 infections in the city of Parnaíba-PI. Methods: This is a secondary descriptive epidemiological study, which used data collected through the COVID-19 case notification form, between March 2020 and 2021, the cases whose cases were not included in the analysis. data in the notification forms were incomplete. Results: The analysis included 11,864 cases diagnosed in the period. Conclusion: The cases analyzed consisted mainly of women, and were mainly in age groups from 20 to 59 years, with a peak incidence in the range from 30 to 39 years. The vast majority did not report comorbidities or risk situations. The most reported symptoms were fever, cough and sore throat.
\end{abstract}

Keywords: SARS-CoV-2; COVID-19; Coronavirus; Health profile.

\section{Resumen}

Introducción: El comportamiento de la pandemia COVID-19 es resultado de varios factores, como las características virales y poblacionales y el uso de medidas para controlar el número de casos. La variedad de dichos factores en cada 
territorio es responsable de crear perfiles epidemiológicos únicos, el estudio de estos perfiles es fundamental para comprender el comportamiento de la epidemia y planificar medidas para combatir la enfermedad. Para ello, el presente estudio propone investigar el perfil de infecciones por el nuevo coronavirus en la ciudad de Parnaíba-PI. Objetivo: Trazar el perfil epidemiológico de las infecciones por SARS-CoV-2 en la ciudad de Parnaíba-PI. Métodos: Se trata de un estudio epidemiológico descriptivo secundario, que utilizó datos recolectados a través del formulario de notificación de casos COVID-19, entre marzo de 2020 y 2021, los casos cuyos casos no fueron incluidos en el análisis. Los datos en los formularios de notificación estaban incompletos. Resultados: El análisis incluyó 11.864 casos diagnosticados en el período. Conclusión: Los casos analizados fueron principalmente mujeres, y se ubicaron principalmente en grupos de edad de 20 a 59 años, con un pico de incidencia en el rango de 30 a 39 años. La gran mayoría no reportó comorbilidades ni situaciones de riesgo. Los síntomas más notificados fueron fiebre, tos y dolor de garganta.

Palabras clave: SARS-CoV-2; COVID-19; Coronavirus; Perfil de salud.

\section{Introdução}

O SARS-CoV-2, causador da síndrome respiratória aguda grave 2, é o mais novo integrante da ordem dos Nidovirales, pertencente à família Coronaviridae. Descritos a princípio na década de 1960, os coronavírus são os maiores víru s de ácido ribonucleico (RNA) conhecidos, possuem cápsula esférica, cercada de proteínas espiculares (proteínas spike) que lhes conferem formato de coroa. O novo coronavírus tem sua identificação datada do final de 2019, na cidade de Wuhan, na China, quando desenvolveu a habilidade de infectar seres humanos. (Bonilla-Aldana, 2020; Chen, 2020). Com alta taxa de transmissibilidade, o novo vírus rapidamente rompeu as fronteiras de Wuhan e alcançou o status de pandemia no início do ano seguinte. O grupo de manifestações respiratórias, digestivas e sistêmicas causadas pelo SARS-CoV-2 foram denominadas de COVID-19 (do inglês coronavirus disease 2019). (Zakary,2020).

As proteínas de membrana do novo coronavírus, proteínas $\mathrm{S}$ (spike), possuem afinidade com os receptores da enzima conversora de angiotensina 2 (ECA-2). É através da ligação entre as proteínas S virais e os receptores ECA-2 celulares, que o coronavírus infecta as células de seu hospedeiro. O amplo espectro, variedade e apresentação de manifestações e sintomatologias, causadas pela infecção do novo coronavírus, se deve a vasta distribuição orgânica dos receptores ECA-2, presentes em órgãos como coração, pulmões, rins, intestino e fígado. Dentre a variedade de manifestações está a assintomatologia, resultante de uma menor replicação viral, porém com potencial de transmissão preservado. (De Souza Carvalho, 2020; Zhou, 2020).

Indivíduos com maior expressão de receptores ECA-2 são propensos à maior atividade viral e a quadros mais graves da COVID-19, e formam o chamado grupo de risco para a doença. Indivíduos obesos, e ou diabéticos apresentam maior expressão de receptores ECA-2 no tecido adiposo e em células semelhantes à adipócitos (lipofiboblastos pulmonares), de modo a tornar o panículo adiposo um grande alvo e reservatório viral, agravando o quadro a nível sistêmico. Além disso, a obesidade também está diretamente ligada a outras condições inflamatórias crônicas, como a hipertensão arterial sistêmica, que predispõem a circulação aumentada de citocinas, que frente ao SARS-CoV-2, exacerbam a resposta inflamatória orgânica e levam a maiores complicações durante o intercurso da doença. (Banerjee, 2020; De Oliveira Santos, L.A, 2021).

A anteriormente abordada vasta distribuição orgânica dos receptores ECA-2, propicia que condições relacionadas a falência orgânica, a exemplo renal e hepática, também cursam com quadros mais graves, uma vez que o vírus ao atacar órgãos já debilitados, exacerba a condição preexistente. A íntima relação entre tais doenças crônicas com o envelhecimento, eleva a taxa de mortalidade dos idosos que contraem a COVID-19. A literatura traz ainda, que nesses pacientes o tempo de incubação viral também é reduzido, o que leva a uma maior agudização dos sintomas. (Rothan, 2020; Wu, Z, 2020).

Porém, casos fatais de COVID-19 não ocorrem só nas populações em grupos de risco, levantando um alerta acerca da importância da prevenção do contágio em todos os grupos. Desse modo, após um ano do início da pandemia, as medidas de distanciamento social, uso de EPI's e higienização das mãos e objetos, ainda são as melhores alternativas para o controle do número de casos, proteção da capacidade dos serviços de saúde e conservação de vidas. Estudos indicam que os países que 
implementaram corretamente tais medidas, foram os que mais rapidamente conseguiram controlar a gravidade do cenário em seu território. (Souza, 2020; Cavalcante, 2021).

Diante do exposto, observa-se que a interação de diversos fatores como o de virulência viral, com as características populacionais, e medidas de contenção da epidemia, geram cenários e perfis epidemiológicos únicos em cada território. A análise destes perfis é primordial para o entendimento do comportamento da epidemia, planejamento de medidas sanitárias e manejo de casos. Desse modo, o estudo atual propõe traçar o perfil epidemiológico dos casos de COVID-19 no município de Parnaíba-PI.

\section{Objetivo}

Traçar o perfil epidemiológico das infecções por SARS-CoV-2 no município de Parnaíba-PI.

\section{Métodos}

Trata-se de um estudo epidemiológico descritivo secundário, realizado no município de Parnaíba-PI, entre os meses de março de 2020 e 2021, tendo sido utilizados 2 meses para coleta de dados. Dados estes, fornecidos pelo setor de vigilância epidemiológica do município. Foram incluídos na análise do estudo todos os casos novos de COVID-19 notificados dentro do período de março de 2020 a março de 2021. Considerou-se como casos novos aqueles que apresentaram o primeiro diagnóstico RT-PCR ou sorológico positivo para infecção por SARS-CoV-2. O mês de março de 2020 foi escolhido pois no mesmo, a organização mundial da saúde declarou que a COVID-19 galgara status de pandemia. (Girardi, 2020).

A pesquisa em questão utilizou-se de dados secundários disponibilizados pelo setor de vigilância epidemiológica da prefeitura do município. O acesso aos dados foi possível através da autorização do setor. Os dados obtidos para a realização deste trabalho não contêm qualquer informação pessoal que seja capaz de identificar os pacientes. Esta pesquisa seguiu os critérios das resoluções número 466/2012 e número 510/2016, do Conselho Nacional de Ética em Pesquisa (CONEP) brasileiro.

Foram incluídos no estudo todos os diagnósticos positivos para COVID-19 tabelados na ficha de notificação, os quais apresentavam todas as informações básicas mínimas necessárias às atividades estatísticas, desenvolvidas por esta pesquisa: SEXO, IDADE e DATA DE NASCIMENTO. Foram excluídos da análise as fichas de notificação incompletas.

As informações presentes na ficha de notificação foram tabeladas e os números absolutos obtidos foram extraídos para o cálculo de percentis, e formulação de gráficos. A análise estatística foi realizada através do software Epi info em sua versão 7.2.4 (de abril de 2020). O software Microsoft Excel, versão 2019 foi utilizado para tabular e gerar gráficos a partir das informações. E o software Iramuteq, versão alpha 7, foi utilizado para realizar análise de corpus textuais. A interpretação das informações resultantes embasou o perfil epidemiológico das infecções por SAR-CoV-2 no município.

Das limitações do estudo, os autores reconhecem o fato das categorias de comorbidades da ficha de notificação não possuírem espaço para especificação da doença do paciente. Ademais, os dados presentes no boletim foram coletados através de entrevista, sendo a principal fonte dos mesmos, os próprios pacientes. Dessa forma, as informações resultantes estão passíveis ao conhecimento prévio dos indivíduos acerca de suas doenças de base.

\section{Resultados e Discussão.}

No contexto de uma pandemia global, de um agente etiológico pouco estudado, polissintomático, altamente transmissível e potencialmente mutável, o primeiro ano da COVID-19 foi marcado por medo, incertezas e um crescente número de mortes $(\mathrm{Katz}, 2020)$. Frente a este desafio, estudar o comportamento da infecção, entender seus fatores de risco e 
compreender o perfil epidemiológico traçado pelo vírus em cada território, constituem vantagens valiosas para o controle e combate do SARS-CoV-2.

Dos 11.868 casos, diagnosticados por meio de testes de reação de transcriptase reversa, seguida de reação em cadeia da polimerase (RT-PCR), e de testes sorológicos tais como imunoensaios de fluxo lateral (LFIAs), ensaios de imunoadsorção enzimática (ELISAs) ou imunoensaios quimioluminescentes (CLIAs), no período selecionado para o estudo, 11.864 foram incluídos, 4 casos constam na ficha de notificação com informações incompletas e tiveram que ser excluídos do estudo. Dos casos incluídos $5.223(44,02 \%)$ foram individuos do sexo masculino, e $6641(55,98 \%)$ do sexo feminino. A razão entre os sexos está representada no Gráfico 1.

Gráfico 1: Sexo dos pacientes diagnosticados com COVID-19.

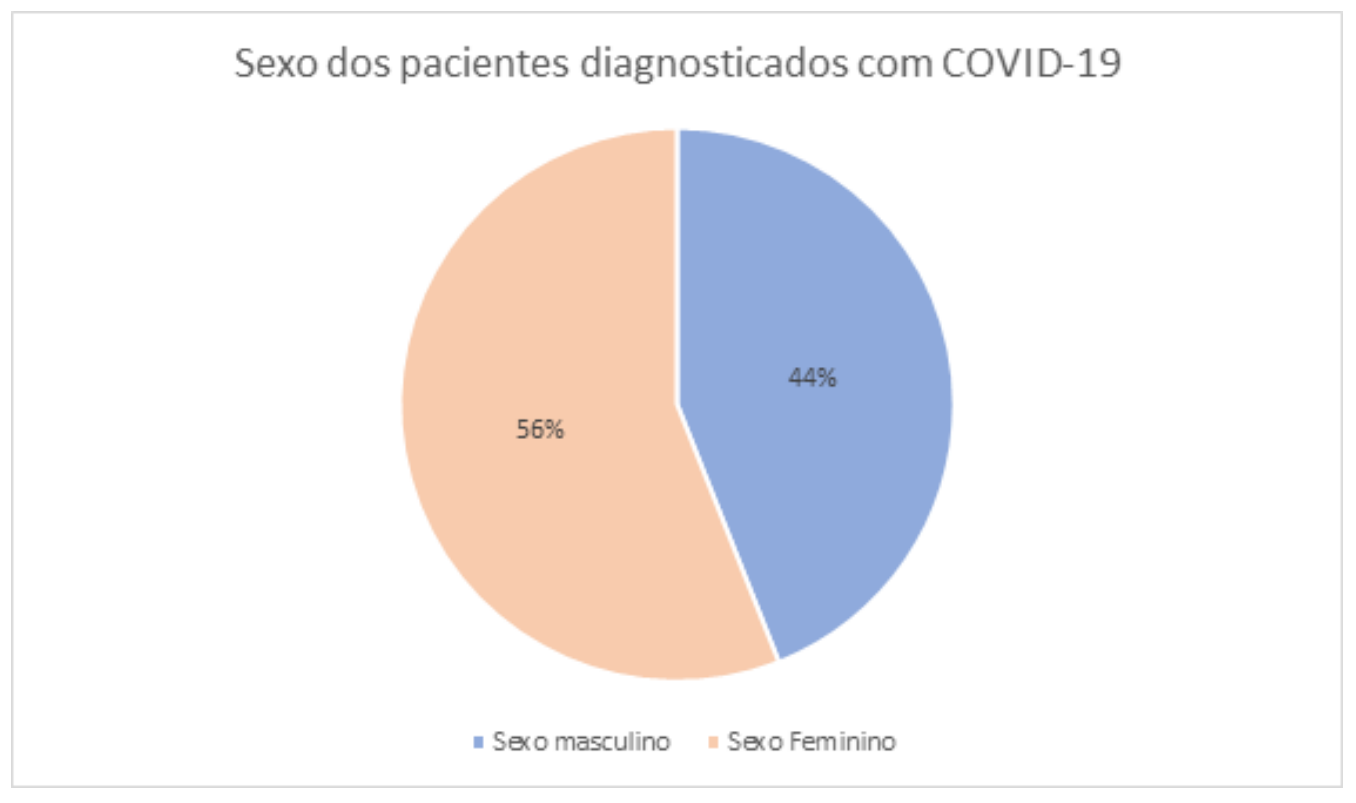

Fonte: Autores.

A dominância do sexo feminino com relação ao número de casos, não necessariamente indica maior tropismo viral pelo sexo em questão, mas pode refletir uma maior procura do sexo feminino pelo serviço de saúde. A pesquisa nacional de saúde (PNAD) desenvolvida pelo Instituto brasileiro de Geografia e estatística (IBGE) realizado no ano de 2019, revela que no ano do estudo, dos 76,2\% da população brasileira que afirmaram terem ido ao médico, 82,3\% foram mulheres. (IBGE, 2020).

No que tange a faixa etária dos casos notificados, observa-se grande concentração de ocorrências na população adulta. As maiores incidências permeiam as faixas entre 20 a 59 anos (74,02\% dos casos), e o pico de incidência localiza-se nas faixas de 30 a 39 anos $(22,50 \%)$. Pode-se entender o fenômeno partindo do princípio que o isolamento social é uma das ferramentas mais eficazes contra a propagação do vírus. Assim, tais faixas, do ponto de vista do mercado de trabalho, são as que tendem a ser economicamente ativas. E por conseguinte, tiveram que se expor mais ao contato com outras pessoas a fim de garantir suas atividades laborais. (Silva, 2020; Aquino, 2020)

Do mesmo modo, crianças e adolescentes (0 a 19 anos) que tiveram suas aulas suspensas em decorrência da pandemia, podendo garantir maior distanciamento social, somaram somente 8,56\% dos casos. De maneira análoga, os idosos ( $\geq 60$ anos) também tiveram sua incidência reduzida, uma vez que estão em uma fase que tende a não ser tão ativa no mercado de trabalho quanto a faixa adulta. Ademais, para esta faixa foram destinadas às maiores recomendações de isolamento social. O número de casos por sexo e faixa etária estão dispostos no Gráfico 2. (Silva, 2020; Aquino, 2020; de Almeida Hammerschmidt, K. S, 2020; Farias, 2020). 
Gráfico 2: Número de casos notificados por sexo e faixa etária.

\begin{tabular}{|c|c|c|}
\hline Sexo Feminino & Faixa Etária & Sexo Masculino \\
\hline 204 & $0-9$ anos & 171 \\
\hline 346 & $10-19$ anos & 294 \\
\hline 1073 & $20-29$ anos & 858 \\
\hline 1482 & $30-39$ anos & 1187 \\
\hline 1247 & $40-49$ anos & 999 \\
\hline 1117 & $50-59$ anos & 819 \\
\hline 625 & $60-69$ anos & 479 \\
377 & $70-79$ anos & 286 \\
134 & $80-89$ anos & 113 \\
30 & $90-99$ anos & 17 \\
6 & $100-109$ anos & 0 \\
\hline
\end{tabular}

Fonte: Autores.

Na ficha de notificação para a COVID-19 utilizada no município, foram incluídas 9 categorias de situação de risco/comorbidades, a serem questionadas no momento da notificação, são elas: doenças cardíacas crônicas; diabetes; doenças renais crônicas em estado avançado; doenças respiratórias crônicas; gestante, imunossupressão; portador de doenças cromossômicas ou estado de fragilidade imunológica; puérpera (parto nos últimos 45 dias) e obesidade.

As situações de risco/comorbidades mais prevalentes dentre as presentes no questionário foram o Diabetes, com 557 notificações (4,69\% do total de casos), logo seguido das doenças cardíacas crônicas, com 556 notificações (4,68\%). Mesmo possuindo estreita relação fisiopatológica entre as duas categorias descritas, os indivíduos que afirmaram ambas as condições, somam somente 156 casos (1,31\%). Dentre as categorias restantes a única que ainda apresentou mais de uma centena de quadros foi a de doenças respiratórias crônicas, com 192 ocorrências (1,62\%). Nenhum dos casos de COVID-19 notificados enquadrou-se na classe de puérpera (parto nos últimos 45 dias). Os números relativos às demais categorias, juntamente com as descritas acima, discriminando os sexos relativos às notificações, estão expostos no Gráfico 3. 
Research, Society and Development, v. 10, n.15, e182101522943, 2021

(CC BY 4.0) | ISSN 2525-3409 | DOI: http://dx.doi.org/10.33448/rsd-v10i15.22943

Gráfico 3: Número de confirmações de situações de risco/comorbidades por sexo.

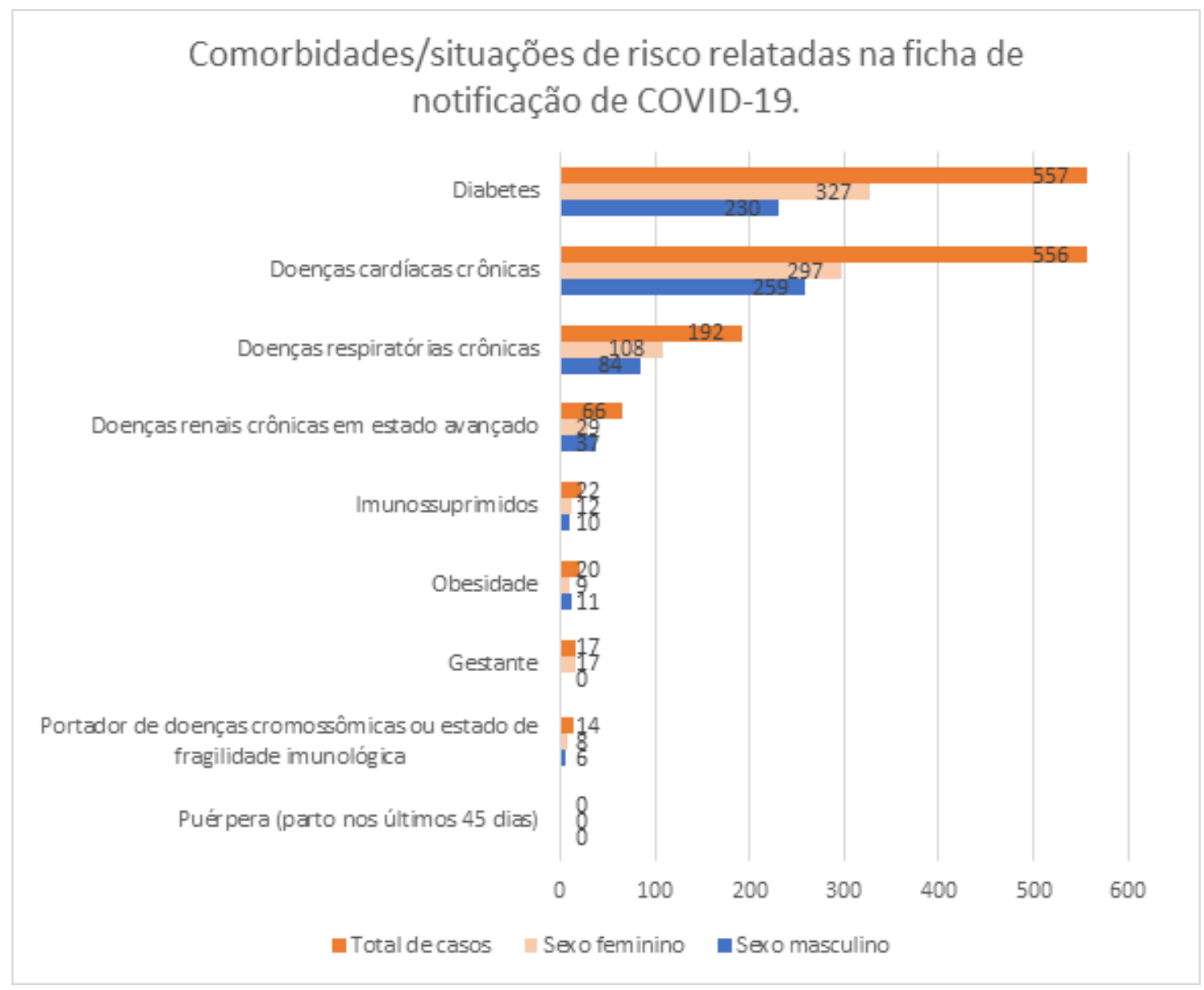

Fonte: Autores.

O número de pessoas que negou situações de risco/comorbidades, 10.658 (89,75\% da das notificações) se faz muito superior aos casos positivos, que afirmaram pelo menos 1 das situações, 1.216 (10,25\%). Uma característica da amostra que justifica esse dado, é que a expressiva maioria dos casos de situações de risco relatadas, se agrupa nas categorias de doenças crônicas (diabetes, doenças cardíacas, respiratórias e renais). E estas em 87,25\% encontram-se em faixas etárias superiores a 60 anos, que configuram somente 17,42\% da amostra total. Em um estudo realizado pelo Chinese Center for Disease Control and Prevention (CCDC), retrata o aumento da letalidade da doença em idosos, variando de 8 a $15 \%$ devido às doenças prévias associadas à faixa etária. (Wu, Z, 2020).

Com relação aos sintomas, o boletim de notificação questiona sobre 9 categorias principais de sinais/ sintomas, são elas: assintomático; coriza; dispneia; distúrbios gustativos; distúrbios olfativos; cefaleia; dor de garganta; febre; tosse e outros. Aos pacientes que preenchessem a categoria outros, há uma linha na ficha para descrição dos mesmos. De todas as categorias acima, a de outros sintomas foi a mais referida, sendo preenchida 6671 vezes (56,23\% dos casos). A segunda sintomatologia mais referida foi a febre (44,86\% das notificações), logo seguida de Tosse $(40,05 \%)$ e dor de garganta $(32,79 \%)$.

Os demais números correspondentes às notificações dos demais sintomas, assim como os das categorias citadas acima estão expostos no Gráfico 4. 
Research, Society and Development, v. 10, n.15, e182101522943, 2021

(CC BY 4.0) | ISSN 2525-3409 | DOI: http://dx.doi.org/10.33448/rsd-v10i15.22943

Gráfico 4: Números de relatos por recorrência dos sintomas presentes na ficha de notificação e por sexo.

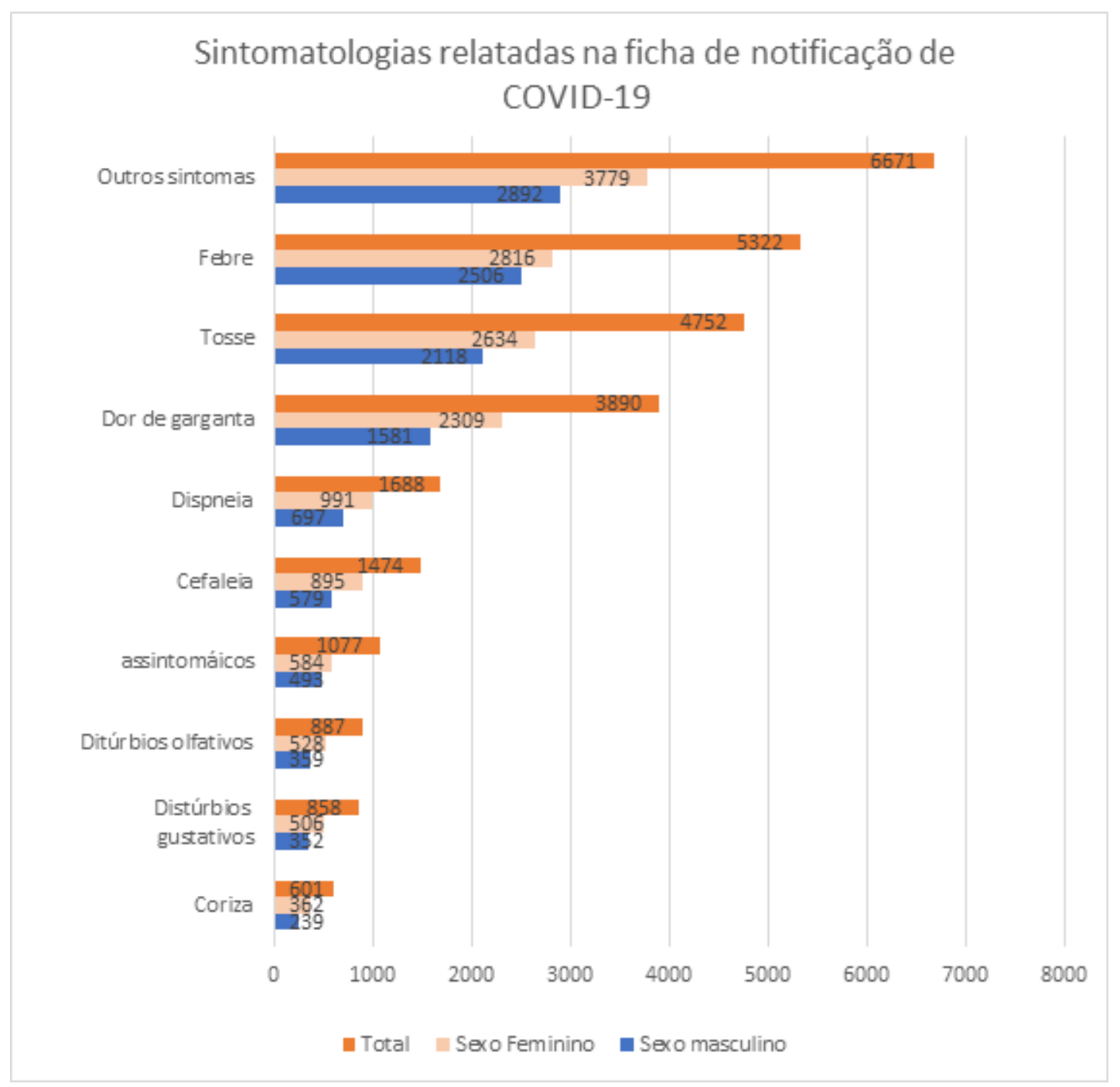

Fonte: Autores.

De acordo com o estudo desenvolvido por Zhou, acompanhando o desenrolar clínico de pacientes assintomáticos de COVID-19, observou-se que pacientes assintomáticos possuem uma carga viral mais baixa, até mesmo do que pacientes em período de incubação da doença. Traçando um paralelo com os estudos de Banerjee e Vaz, sobre a tendência de maior replicação viral em pacientes obesos, com distúrbios insulínicos e ou doenças cardíacas crônicas, conclui-se que casos assintomáticos tendam a ocorrer em pacientes que não possuem tais comorbidades. (Zhou, 2020; Banerjee, 2020; Vaz, 2020).

Os resultados obtidos através da análise da amostra do estudo atual vão de encontro com o paralelo levantado. Dos indivíduos ditos assintomáticos, 988 (91,74\%) negam todas as comorbidades/ situações de risco listadas na ficha, e destes 856 (87,55\%) possuem menos de 60 anos. Crê-se ainda, que o número de indivíduos assintomáticos seja exponencialmente maior que os diagnosticados, uma vez que no Brasil, não foram adotadas condutas de testagem em massa. (Katz, 2020).

A respeito da seção destinada à descrição dos sintomas, a mesma apresenta dados subjetivos, com a presença de muitos termos e elementos textuais diferentes e excede a capacidade do programa estatístico utilizado para o cálculo de frequência. Desse modo, para o estudo deste componente foi utilizado o software iramuteq, a fim de analisar o corpus textual e revelar as outras queixas de maior recorrência.

Através do estudo do corpus observou-se que o espaço de descrição dos sintomas não fora utilizado somente para descrever os outros sintomas, além dos já presentes na ficha, servindo muitas vezes para colocar por extenso aquilo já 
assinalado. A análise revelou dois principais sintomas relatados: mialgia com 1041 citações e diarreia com 830 citações. Tais sintomas foram dispostos graficamente com os demais em comparação à incidência no Gráfico 5 .

Gráfico 5: Comparativo das notificações totais dos sintomas de COVID-19.

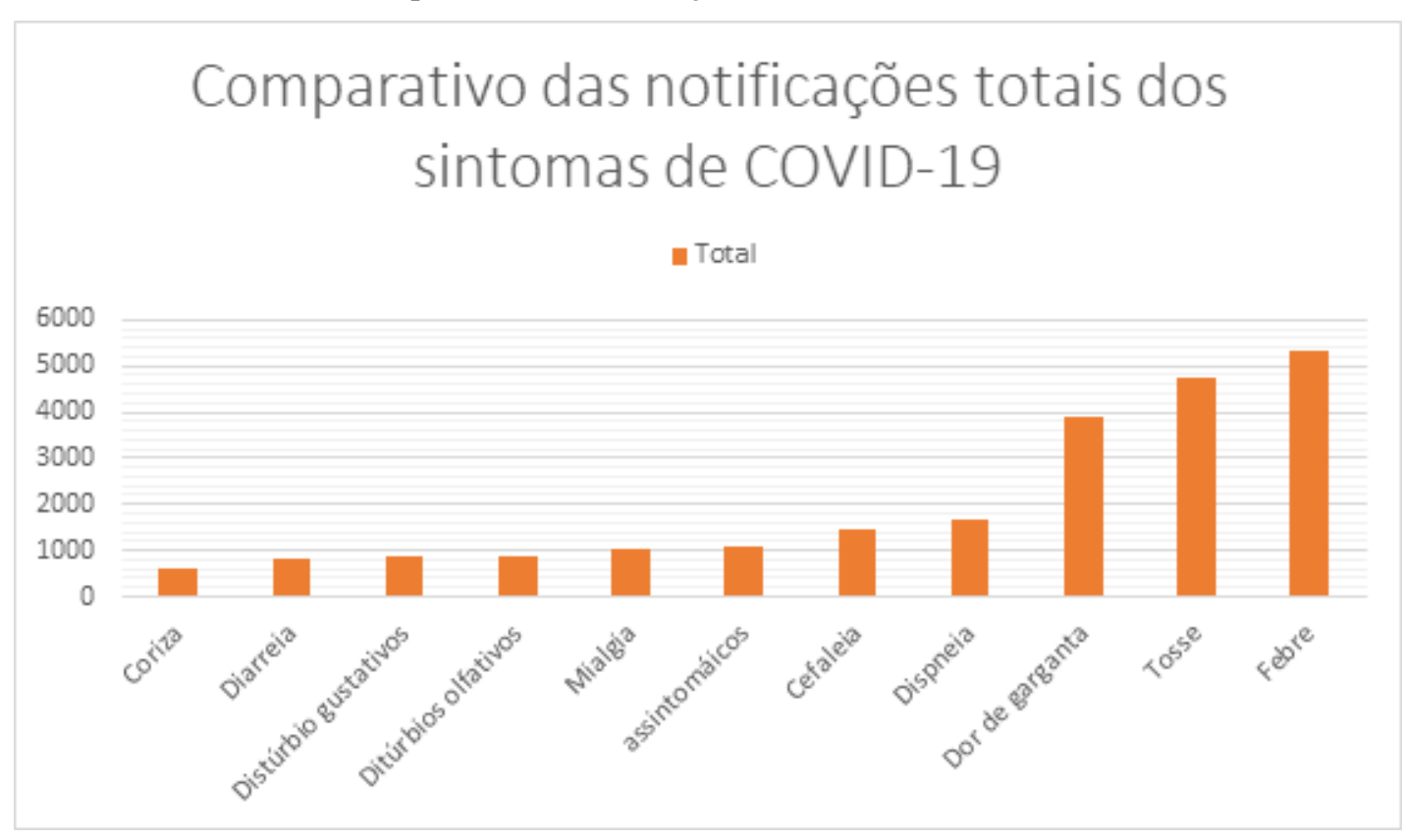

Fonte: Autores.

O estudo conduzido por Chen, analisando 99 pacientes positivados teve como principais sintomas: febre (82\%), tosse (82\%), dispneia (31\%) e mialgia (11\%). Rothan traz em sua análise que os principais sintomas giram em torno principalmente de febre, tosse e fadiga. Na revisão promovida por Iser, confirmaram-se os mesmos sintomas descritos por Rothan como os mais comuns. No geral, os sintomas mais comuns encontrados na amostra vão de encontro com o quadro viral geral e inespecífico descrito na literatura, no qual está presente principalmente febre, manifestações respiratórias, fadiga e dor muscular (Chen, 2020; Rothan, 2020; Iser, 2020).

\section{Conclusão}

Conclui-se que as infecções por COVID-19 notificadas no município de Parnaíba-PI, no período de março de 2020 a março de 2021, foram constituídas principalmente de mulheres. Os casos se apresentaram principalmente em faixas etárias de 20 a 59 anos, com pico de incidência na faixa de 30 a 39 anos, reforçando o impacto do isolamento social para a contenção da transmissão da doença. A grande maioria não relatou comorbidades ou situações de risco. Dos sintomas presentes na ficha de notificação, os mais relatados foram febre, tosse e dor de garganta. Dentro do âmbito para outras sintomatologias as mais referidas foram mialgia e diarreia. Indivíduos assintomáticos, que cursam com menor replicação viral, ocorreram em sua ampla maioria na ausência de obesidade e comorbidades insulínicas, cardiovasculares, renais e pulmonares.

A equipe deste artigo recomenda aos autores de trabalhos futuros, que ao adotarem uma metodologia semelhante, realizem o máximo de comparativos possíveis na literatura com os achados de seus respectivos trabalhos, a fim de gerar discussões ricas e que revelem diferenças nas apresentações, e peculiaridades próprias dos perfis epidemiológicos traçados. 
Research, Society and Development, v. 10, n.15, e182101522943, 2021

(CC BY 4.0) | ISSN 2525-3409 | DOI: http://dx.doi.org/10.33448/rsd-v10i15.22943

\section{Agradecimentos}

Agradecemos aos orientadores do atual trabalho, pela dedicação e apoio durante todo o percurso da pesquisa. Ao mestre, professor José Lopes Pereira Junior por seu inestimável apoio na redação, edição técnica, revisão idiomática e revisão final e à professora, mestra Renata Paula Lima Beltrão pelo incentivo e orientações primordiais para a tomada do tema e definição do desenho de estudo.

\section{Referências}

Aquino, E. M., Silveira, I. H., Pescarini, J. M., Aquino, R., Souza-Filho, J. A. D., Rocha, A. D. S., ... \& Lima, R. T. D. R. S. (2020). Medidas de distanciamento social no controle da pandemia de COVID-19: potenciais impactos e desafios no Brasil. Ciência \& Saúde Coletiva, 25(suppl 1), 2423-2446.

Banerjee, M., Gupta, S., Sharma, P., Shekhawat, J., \& Gauba, K. (2020). Obesity and COVID-19: a fatal alliance. Indian Journal of Clinical Biochemistry, 18.

Bonilla-Aldana, D. K., Dhama, K., \& Rodriguez-Morales, A. J. (2020). Revisiting the one health approach in the context of COVID-19: a look into the ecology of this emerging disease. Adv Anim Vet Sci, 8(3), 234-237.

Cavalcante, F. J. S., Nascimento, I. R. D., \& Cavalcante, R. M. S. (2021). EPIs e segurança dos trabalhadores de saúde durante a pandemia de COVID-19: Uma breve reflexão. Research, Society and Development, 10(7), e55010716809-e55010716809.

Chen, N., Zhou, M., Dong, X., Qu, J., Gong, F., Han, Y., ... \& Zhang, L. (2020). Epidemiological and clinical characteristics of 99 cases of 2019 novel coronavirus pneumonia in Wuhan, China: a descriptive study. The lancet, 395(10223), 507-513.

De Almeida Hammerschmidt, K. S., \& Santana, R. F. (2020). Saúde do idoso em tempos de pandemia COVID-19. Cogitare enfermagem, 25.

De Oliveira Santos, L. A., Campelo, Y. D. M., Beltrão, R. P. L., de Souza Mendonça, G., da Silva, V. A., \& de Brito Campelo, V. M. (2021). Análise da taxa de eficácia dos testes sorológicos rápidos para COVID-19 registrados na ANVISA, uma revisão sistemática na literatura. Research, Society and Development, 10(11), e264101119615-e264101119615.

De Souza Carvalho, F. R., Gobbi, L. C., Carrijo-Carvalho, L. C., Caetano, A. J. F., Casotti, G. C., Tiussi, L. M., \& Cavalari, A. L. C. (2020). Fisiopatologia Da Covid-19: Repercussões Sistêmicas. Unesc em Revista, 4(2), 170-184.

Farias, H. S. D. (2020). O avanço da Covid-19 e o isolamento social como estratégia para redução da vulnerabilidade. Espaço e Economia. Revista brasileira de geografia econômica, (17).

Girardi, G. (2020). OMS declara pandemia de novo coronavírus; mais de 118 mil casos foram registrados. O ESTADO DE SÃO PAULO. Publicado em, 11.

IBGE- Instituto Brasileiro de Geografia e Estatística. (2020). Pesquisa nacional de saúde: 2019: informações sobre domicílios, acesso e utilização dos serviços de saúde: Brasil, grandes regiões e unidades da federação / IBGE, Coordenação de Trabalho e Rendimento. https://biblioteca.ibge.gov.br/visualizacao/livros/liv101764.

Iser, B. P. M., Sliva, I., Raymundo, V. T., Poleto, M. B., Schuelter-Trevisol, F., \& Bobinski, F. (2020). Definição de caso suspeito da COVID-19: uma revisão narrativa dos sinais e sintomas mais frequentes entre os casos confirmados. Epidemiologia e Serviços de Saúde, 29.

Katz, L. (2021). Aspectos gerais da pandemia de COVID-19. Revista Brasileira de Saúde Materno Infantil, 21, 29-45.

Rothan, H. A., \& Byrareddy, S. N. (2020). The epidemiology and pathogenesis of coronavirus disease (COVID-19) outbreak. Journal of autoimmunity, 109, 102433 .

Silva, L. L. S. D., Lima, A. F. R., Polli, D. A., Razia, P. F. S., Pavão, L. F. A., Cavalcanti, M. A. F. D. H., \& Toscano, C. M. (2020). Medidas de distanciamento social para o enfrentamento da COVID-19 no Brasil: caracterização e análise epidemiológica por estado. Cadernos de Saúde Pública, 36, e00185020.

Souza, A. S. R., Amorim, M. M. R., Melo, A. S. D. O., Delgado, A. M., Florêncio, A. C. M. C. D. Oliveira, T. V. D., \& Katz, L. (2021). Aspectos gerais da pandemia de COVID-19. Revista Brasileira de Saúde Materno Infantil, 21, 29-45.

Vaz, I. C. O. G., Cassimiro, R. D., \& Soares, V. (2020). Influência de doenças cardiovasculares e obesidade no quadro clínico de pacientes com a covid-19. Anais da Mostra Acadêmica do Curso de Fisioterapia, 8(1), 108-114.

Wu, Z., \& McGoogan, J. M. (2020). Characteristics of and important lessons from the coronavirus disease 2019 (COVID-19) outbreak in China: summary of a report of 72314 cases from the Chinese Center for Disease Control and Prevention. Jama, 323(13), 1239-1242.

Zakary, O., Bidah, S., \& Rachik, M. (2020). The Impact of Staying Home on Controlling the Propagation of COVID -19: Control Strategy. Mexican Journal of Biomedical Engineering, 42 (1), 10-26.

Zhou, R., Li, F., Chen, F., Liu, H., Zheng, J., Lei, C., \& Wu, X. (2020). Viral dynamics in asymptomatic patients with COVID-19. International Journal of Infectious Diseases, 96, 288-290. 